\title{
The ethical and social implications of age-cheating in Africa
}

\author{
Mbih Jerome Tosam \\ Department of Philosophy, Higher Teacher Training College Bambili, The University of Bamenda, Bamenda, Cameroon
}

\section{Email address:}

mtosam2002@yahoo.com

\section{To cite this article:}

Mbih Jerome Tosam. The Ethical and Social Implications of Age-Cheating in Africa. International Journal of Philosophy. Vol. 3, No. 1, 2015, pp. 1-11. doi: 10.11648/j.ijp.20150301.11

\begin{abstract}
This paper examines the ethical and social implications of a particular form of corruption in Africa-age-cheating. Although age-cheating is a global issue, it has received very little academic attention from social philosophers. In this paper I argue that there exists an inextricable link between bad governance, economic hardship, and the collapse of moral values in most African countries. Using Cameroon as an example, I maintain that age-cheating is one of the several corrupt ways citizens in most post-colonial African states use as a way out of unemployment, chronic poverty, and political and economic deprivation. Also, age-cheating is common in African countries where the civil registration system is either archaic or completely inexistent. I argue for the view that a vibrant democratic culture would help to promote values like accountability, transparency, and the rule of law which may enhance governance and economic development as democracy promotes political and economic rights and freedoms. In this direction, I suggest that, in tandem with democracy, the new information and communication technologies (ICTs) may be helpful in improving transparency in the domain of civil registration in particular and state governance in general.
\end{abstract}

Keywords: Age-Cheating, Ethics, Economic Hardship, Biometric Registration, Good Governance, Africa, Cameroon

\section{Introduction}

This paper critically examines the ethical and social implications of the phenomenon of age-cheating in Africa with particular emphasis on Cameroon. However, from time to time cross references will be made to other African countries; to show that age-cheating is caused by lack of good governance which has resulted in economic hardship and the collapse of moral values in most post-colonial African states. Harsh living conditions in these countries have forced their citizens to look for diverse unscrupulous means of survival. Undemocratic methods of governance (lack of transparency, accountability and the rule of law) have had damaging effects on economic and social life(like economic deprivation, tribalism, abuse of human rights and lack of opportunities) in most post-independent African states In Cameroon, like in most African states hit by economic hardship, unemployment is growing and the gulf between the rich, ruling minority, and the impoverished masses, is wideningin a country which "counts among the wealthiest and most highly educated on the African continent" (Tangwa, 2014).To reduce the widening poverty gap, most
Cameroonians/Africans tend to either reduce or increase their ages, to suit job requirements in the civil service and especially in sports like football which has become very lucrative abroad.

Although age-cheating is a global moral issue, apart from the avalanche of scholarly works on academic cheating and cheating in professional sports, there is paucity of academic works on age-cheating. It is also important to note that among the several studies on corruption in Africa and Cameroon in particular (Titi Nwel, 1999; Ofege, 2004; Mbaku, 2007), there has been no focus on age-cheating as a form of corruption. This paper therefore defends the argument that there exists an intimate connection between bad governance, economic hardship, and corrupt practices like age-cheating. Nonetheless, this does not imply that agecheating exists only where there is bad governance and economic hardship; it is a global issue, although very common in Africa for various reasons. Before delving into age-cheating in Africa, it is germane to understand the phenomenon. 


\section{What is Age-Cheating}

To understand what is meant by age-cheating, it would be useful to understand what is meant by cheating. To cheat is to trick, deceive, swindle, or simply violate the rules of a game. We cheat someone of or out of something if we trick or deceive them so as to gain undue advantage over them. To cheat is to act dishonestly or to take advantage of the other's trust. In this sense, there is a close link between cheating and corruption. Both cheating and corruption involve the deliberate use of dishonest means for self-interest such as lying, falsifying, distorting, and defrauding. Some forms of cheating include adultery, tax evasion, non-respect of the rules of a game, intentionally overbilling customers, nonrespect of promises (Allen 2002: 28-57), secretly receiving undeserved advantages or allowances, receiving remuneration for a job not done, and falsification of documents. 1

Otherwise known as age-fraud orange-fabrication, agecheating is the use of false documentation to show that one is either younger or older than his/her real age with the intention of gaining advantage over competitors. Age-cheats may appear younger or older on paper than their real ages(for the most part they appear younger). In most African countries and especially in Cameroon today, age-cheating has become a culture. The practice of age-cheating has become so common that some people find nothing ethically wrong with it, and, even if others find it morally wrong, they consider it a necessary evil - a means of survival in a situation of total deprivation and poverty.

There are several names for age-cheating and false documentation in Cameroon. Some of the names are associated with the localities, neighborhoods, and/or towns that champion the fabrication of false documents. These include "Bonas", the abridged name for Bonamousadi, the overcrowded, squalid, and crime-infested student residential area in Yaoundé, where some dropouts and unemployed graduates make a living out of false documentation. There, if you want any document/certificate, a B.A. M.A. or a $\mathrm{PhD}$, or even a document from the Presidency of the Republic of Cameroon, you may have it. (http://www.africanindependent.com/cam_corruption_ntemfa c01.html). Another very popular name for false documentation is "Kumba."This refers to a town in the South West Region of Cameroon which has become an abode of such fraudsters and forgers. In Cameroon today if you present any official document issued in Kumba, its authenticity is almost always questioned without verification. Most people who have obtained an official document from Kumba have suffered delays or rejection of their files in different offices and especially in foreign embassies on suspicion that their papers might be fake. Sometimes, a false document is simply referred to as "docky." As concerns agecheats in particular, they are sometimes referred to as "born agains." Of the four names commonly used to denote false documentation, "Kumba" is the most popular.

The culture of age-cheating in Cameroon can be traced back to the 1960 s after the country gained 'independence.' Since then the phenomenon has grown in breadth and depth. In the 1960s and 1970s, most people falsified their ages to appear older in order to qualify for the newly created jobs in the public service like the armed forces, nursing, and teaching. But during the last two decades or so, with the evergrowing rate of unemployment, underemployment, and poverty, the phenomenon has not only changed, but has become more drastic and pervasive. Today, most people reduce their ages to appear younger with some appearing 10 or 20 years younger on paper than their biological ages.

\section{Age-Cheating in Africa}

In examining the phenomenon of age-cheating in Africa, I have focused my attention on two main areas where the disease is common-age-cheating in the public service and age-cheating in the domain of sports.

\subsection{Age-Cheating in the Public Sector}

In the public sector in Africa, the culture of age-cheating is very common. Most graduates who do not have a means of survival resort to age-cheating.

While carrying out research on this paper, I interviewed a number of youths in Yaoundé and Bamenda to have their opinion about the phenomenon of age-cheating in Cameroon. Three of these responses are powerfully edifying. Here is what the first had to say (which somehow summarizes the general view expressed by most young people):

I don't find anything morally wrong with age-cheating; it is a game encouraged by the Biya regime. Look at him and his close collaborators, most of them are above 70. When some of us were in primary and secondary schools in the late 1980s and early 1990s, they (politicians) used to tell us we were the leaders of tomorrow, but more than 30 years after, the very people who used to tell us we were the leaders of tomorrow are still there, not thinking or willing to leave the scene someday. Today, they are still telling the same old stories to our kids. Our politicians have redefined the concept of youth. They claim that being young is not a matter of chronological or biological age, but a 'state of mind.' "What does this mean?" It means that even if you are 80 and still feel physically and mentally strong, you are a youth. Today they are using their illegitimate positions to place their children and grandchildren in strategic places in the state apparatus. Is this the future they promised? There is no future for us and may be none for our children and grandchildren, if things do not change. So, my brother, if you have an opportunity to secure a job for yourself and the age limit thing is an obstacle, I don 't see anything morally wrong with 'cutting' even up to 20 years especially for a 45 year old unemployed graduate and parent like me. 
From this perspective, age-cheating is a way of fighting economic deprivation and disenfranchisement of the people caused by several decades of political exclusion, squandermania, and economic stagnation in most postindependent African countries.

Another graduate, who is today a civil servant, told me that age-cheating is a means of survival, considering the high level of unemployment and economic hardship in Cameroon. She narrated her story thus:

When I succeeded in the entrance exam into the Higher Teacher Training College (ENS) Yaoundé, I was already 38 and this was 14 years after I graduated from the university. I have never had anything I could really call a job. During these years, I passed the written part of the entrance exams into ENS and failed the oral part twice. I also passed the entrance into the Advanced School of Administration and Magistracy (ENAM) once. Here, my name was on the waiting list. While the other candidates with whom I was on the waiting list were called up, I was not. I was asked to bring the sum of Imillion Francs CFA. I could not afford that amount. So, imagine if I just gave up because I had crossed the 32 year age limit.

Age-falsification, it should be noted, may not necessarily be a solution to the problem of unemployment. Sometimes you may have to falsify in combination with other corrupt practices before you succeed. It is in this light that she argues:

Reducing your age is not a guarantee. I went to the university where I graduated and "saw a few people" and my age was "adjusted" on my transcripts and attestation. I was 28 when I succeeded the entrance exams into ENS in 2008. This time I was lucky to have a brother-in-law who is closed to someone in a high office. In this country, if you don't have money to buy a place for yourself or someone in a high office to make a phone call, you are doomed.

Sometimes you need to have both the cash and the 'connection' to secure a place for yourself. Having the money at times is not enough because this is also fertile ground for conmen

The third is a discussion I had with a 34 year old primary school teacher who is a not satisfied with his salary and has looked for a way of solving the problem in the nearest future. He said he has changed his name and reduced his age and has written and passed the GCE Ordinary Level and is now preparing for the Advanced Level. With the new identity, he intends to go to the university, get a degree and look for a better job and drop the one he already has. I asked how he was to manage studies and his job. He said he intends to look for someone to teach in his place for a little pay and shall make a deal with his head teacher and inspectors to cover him up.

The example of this primary school teacher is a paradigmatic case of duplicity of identity common in public service in most African countries. Although he intends to drop his current job whenever he succeeds to have a better one, it is not unusual with most people who have succeeded in multiplying their identities and are on the state's payroll. He may keep both jobs, as most people with double identity do, so long as there is someone to cover him up and/or so long as his new identity is not known. Every year the government of Cameroon takes measures to purge such dubious persons from the state's payroll, but such measures are usually unproductive because of corruption among those who are supposed to do the purging. This is not only common in Cameroon. For example, in 2014 the Nigerian government uncovered 1050 cases of age cheats in the public service(article.wn.com/view/.../Govt_Uncovers_1050_Age_ Cheats_in_Civil_Servic).

From the foregoing views, it is evident that age-cheating is used as a means of survival in a system that no longer cares about its youth and is determined to maintain the statusquo for the interest of the ruling elite. Also, there is no doubt from the concerns of some young Cameroonians that there is an intergenerational tension between the youths and the ruling elites who, by refusing to retire or create a fair and transparent environment for youths' employment, block the promotion and recruitment of younger workers. This does not only encourage age-cheating but also create a fertile ground for political turmoil which is recurrent in post-independence Africa. The above view summarizes the general feelings of the youths in most African countries. In 2010 the government of Cameroon launched a huge programme to recruit 25000 unemployed Cameroonians into the public service. The programme extended the age limit to 40 , far beyond the 32 year age limit usually applied in recruitment into the public service. Some political observers have argued, and correctly, that the Cameroon government was forced to take such measures as a way of deterring the youths from taking to the streets, to avoid uprisings similar to the Arab spring which began in Tunisia in 2010, with unemployment as one of the principal causes. However, in spite of this, the unemployment situation in Cameroon has not changed because of several decades of increasing unemployment.

The abuse of power, the reluctance to retire by the ruling elite, and corruption also encourage age-cheating. In most African countries, the ruling elite govern the state as though it were their private property, where they decide what, what quantity, and on what basis to give out, or share part of that estate with some of their acolytes. Appointments are more or less a sort of compensation to some individuals or groups for their loyalty to the president.

\subsection{Age-Cheating in African Sports}

The domain where the disease of age-cheating seems incurable in Africa is in the domain of football. In fact, agecheating is for African football what doping is for European and American sports. Some infamous examples of sports fraud in the recent past include: Lance Armstrong, considered the biggest cheat in the domain of professional sport. Armstrong was found guilty of organized doping for most of his career. After being diagnosed with cancer in 1997 and 1998, Armstrong came back to win one of the most difficult 
sporting events in the world, the Tour de France, seven consecutive times. Other examples include the Canadian sprinter, Ben Johnson in the 1988 Olympic Games; Floyd Landis in the 2006 Tour de France; American sprinter, Marion Jones in the Sydney Olympic Games in 2000;Spanish cyclist, Alberto Contador in the 2007 Tour de France; American baseball star, Mark McGwire in 2010; and Irish swimmer, Michelle Smith in the 1996 Atlanta Olympic Games.

In African sports the disease is not doping; it is agecheating. The phenomenon of age-falsification is so common in African football that most players in junior leagues always almost have two or three ages, one real, and the other(s), or all, false. Football age and real age are some distinctions known to even uncritical observers of football in Africa/Cameroon. One of the infamous examples of agecheating in African football is the case of the Cameroonian international footballer, Tobie Mimboe, who held several documents during the course of his career which showed he became younger as the years passed (Mungazi, 2010). Since then, there have been several cases of accusations and suspicions of age-fraud. For example, the former Nigerian defender, Taribo West; Ghanaian footballer, Ben Clottey; and a recent case that caused FIFA to open an investigation is that of Congolese player, Chancel Mbemba Mangulu. According to the registration of his first two Congolese clubs, Mbemba was born in 1988. But for a Cup of Nations qualification match in June 2011, his birth date was recorded as November 30, 1991. Meanwhile, the date of birth registered by his Belgian club Anderlecht is August 8, 1994. And, as if that is not enough complication, according to Mbemba, he was born in1990 (http://edition.cnn.com/2013/02/01/sport/football/ageafrican-football-mbemba/).

Another controversy about age-fraud concerns former Chelsea Cameroonian striker, Samuel Eto'o. In a leaked conversion in 2014, his manager, Jose Mourinho, said he may be more than 34 years, and Eto'o's ex girl friend says the player may be actually 39 http://www.dailymail.co.uk/sport/football/article2568284/Sa muel-Etoo-annoyed-Jose-Mourinhos-jibe age.html). Whether this is true or not, this controversy brought, once more, to the fore, the issue of age-cheating in African football.

Moreover, most successful African youth teams have been accused of age-cheating over the years. But so far, only Niger has been "officially disqualified"(Guest, 2009) from a youth championship in 2009. The Gambia, for example, which has never qualified for the senior World Cup, has been twice African under 17 champions (2005 and 2009). Critics argue that one of the reasons why African teams are so successful in junior FIFA championships but perform poorly in senior championships is because most African teams use over-age players who are physically and mentally more mature and experienced (Guest, 2009) in the game than teams which use players with their correct ages, so that by the time the players reach the senior level, where they are expected to mature, they are already worn out. African teams have won 5 of the 13 FIFA junior competitions, but have never gone beyond the quarter-finals at the senior level. Logically, it is expected that a good junior team should make a good senior team, but this is not the case with most African teams. A good example is the current Spanish senior football team in which most of its players played together at the junior levels and has won the European Cup twice, 2010 and 2012, and also won the 2010 World Cup. Why is this phenomenon common in African football?

According to Cora Burnett, in football, the situation is more complex. Burnett considers poverty as the principal reason why young people falsify their ages in football. She argues:

You have to understand the social world of professional sport and the dreams of young boys to make it in sport. As [only] about $0,005 \%$ actually succeed in making a living out of sport the pressure is there, especially for youngsters living in chronic poverty, to find a pathway that may lead to a career in sport. For these young boys the pressure is on to find a position in a team, where the competition is fierce. Pressure from the coach and parents ... may also contribute to the overage syndrome. The context that about $20 \%$ of children in rural areas and impoverished communities do not have birth certificates or valid [identity] documents leaves the gap for unethical conduct [concerning age] (Burnett 2008).

This observation is telling. It captures the plight and pressure most youngsters in African countries face. Economic adversity, poverty and the lack of alternative means of survival, caused by several decades of economic deprivation, is one of the main reasons why they resort to age-cheating. Moreover, most African countries lack organized football/sports championships where young talented athletes can be discovered. For this reason, it takes too long for most athletes to be noticed by foreign clubs. In order not be rejected by these clubs, when that opportunity comes, because of their age, the players are forced to reduce their ages (http://www.bbc.com/sport/0/football/26174252).

\section{Causes of Age-Cheating}

One of the foremost reasons for age-cheating in African is the high level of unemployment/underemployment in most African countries (in some countries it is about 60). In Cameroon, for example, the government is the main employer. The very weak private sector, coupled with job insecurity and low wages, compel most Cameroonians to dread the private sector. In the public sector, job security is guaranteed, and although wages are low, one is sure to have a salary at the end of the month. Moreover, there is inertia and laxity in the public sector (Ebai and Forje, 2009) such that you may be able to do other jobs to complement the low wages which is not possible in the private sector. Those in the private sector usually work extra hours for little or no compensation.

Another important reason for age-cheating is the lack of an efficient civil registration system. Age-cheating is common in 
countries where the civil registration system is antiquated or totally inexistent. In most rural areas and even in some cities in Africa, children are born at home, and are hardly ever registered on the civil registry. In Cameroon some children only have their birth certificates when they are preparing to sit the First School Leaving Certificate (FSLC) exams, where this important document is a necessary registration requirement. In most cases, people only guess their ages. Sometimes parents, most of whom are illiterates, cannot remember the exact year, month and day their child was born. In some cases they may only be able to recall the season or event leading to the birth and not the exact month, day or year. Underscoring the point of approximating age in Africa, and talking about his own age, the Ugandan President, Yuweri Museveni, explains:

I use the word "about" because my parents were illiterate and so did not know the date. In such circumstances dates were associated with events. Parents would tell their children: You were born when such and such an event took place. We who know how to read and write can now look back and use all sorts of sources to find out what was happening at the time. That is how I came to the conclusion that my numerical birth date must be 1944 or 1945, but more likely 1944 (Museveni, 2005).

Because of the lack of this important personal information, fraudsters find it easy to falsify from the simplest personal document to a $\mathrm{PhD}$. You can change your name, date and place of birth as you see fit or as the situation requires. Some people have different ages and use them depending on the circumstance.

Moreover, the African cultural practice of classifying people according to developmental stages is an important contributing factor which facilitates age-cheating. In most African cultures, those who become responsible at an early age are graded in a particular age group, sometimes higher than their real age. It is from this perspective that Cleveland contends: "African age systems include formal age classes (for age sets of individuals of similar numerical age, age grades, or development stages based on social and biological development" (Cleveland, 1987). These determinants of age are usually inexact because people's ages are determined based on "their abilities, capacities, and social roles rather than their exact birth date" (Cleveland, 1987). For instance, "an 18 year old who is married with children would be treated as of a different age than an 18 year old finishing school and playing soccer" (Guest, 2009). It is therefore difficult, in such a culture, to tell the exact age of a person because some people mature, physically and intellectually, faster than others. With such a cultural outlook on age, coupled with an archaic civil registration system or lack of it, the possibility of using the wrong age or of deliberately altering ages on official documents becomes very easy.

In some cases, graduates who realize that they are already getting passed the 32 years age limit to take any exams into the public service (as I have argued above), may decide to make a new birth certificate with a new birth date, a much younger age, rewrite the GCE (General Certificate of Education) Ordinary and Advanced Levels, and look for fraudulent means to have their dates of birth, and even marks, if their intention is to have a better grade, on their certificates, changed to correspond with the new date (http://recorderline.blogspot.com/2009/06/cameroon-whencertificates-are-cooked.html). In other cases, some people take completely new names. There are cases where people, less qualified, or even more qualified, but jobless, impersonate a brother or sister who is either deceased or have travelled abroad. The negative effect of this practice on the quality of service and on the economy as a whole is devastating. For example, imagine the danger, on the population, of someone who passes for a nurse, medical doctor or teacher. This has direct adverse effect on development because the output of such workers is usually low.

Moreover, as the political elite prolong their stay in power, the youths, both employed and unemployed, look for various ways of increasing their chances of securing an employment or extending their working years through age-cheating. Achilles Mbembe has observed that because of the abuse of power and dispossession characteristic of the post-colonial state, “...the subjects in the post colony have also had to have a marked ability to manage not just a single identity for themselves but several, which are flexible enough for them to negotiate as and when required" (Mbembe, 1992).

In Cameroon today, a presidential or ministerial appointment could keep you from retiring even several years after you are due retirement. The government policy is that once you have been appointed, unless you are replaced, you cannot retire. It is for this reason that some civil servants who should have long retired, have stayed in their positions until their death. Also, because of low salaries and the economic hardship, most civil servants in Cameroon dread retirement. For this reason, when some people are about to retire, they look for all unscrupulous means to be appointed or to prolong their retirement date. Sometimes it is by moving from the opposition party to the ruling party. (http://www.africanindependent.com/cam_corruption_ntemfa c01.html). All of these encourage age-cheating because as the ruling elite and their associates cling to power, they prevent the youths and other dispossessed persons from also climbing the ladder of power or partaking in governance. As those in power push their retirement dates further, the young and those who have not had the opportunity to secure a job for themselves also want to increase their chances of securing a job by falsifying their ages.

Furthermore, the economic crisis that hit the country and most of the continent of Africa in the late 1980s and early 1990s, followed by the devaluation of the Francs CFA, and the $70 \%$ reduction of the salaries of Cameroon civil servants in 1993, led to untold misery and the pauperization of the Cameroonian civil servant. In this situation of hardship, most civil servants have resorted to corrupt means of making additional income. To overcome this situation, some civil servants have reduced their ages so as to stay longer in the 
public service.

The reason for the high level of unemployment in most African countries today can be attributed to the fact that the educational systems, which are still basically colonial in nature, lay more emphasis on tertiary education and less on professional and industrial education. After independence, the target of most African states was to have citizens who could read and write while other parts of the world were trying to transform their citizens into job creators and creators of capital. The origin of this phenomenon can be traced back to the colonial era. As Oba and Eboh maintain, "colonialism and education are two main ways through which European powers perpetuated the underdevelopment of Africa" (Oba and Eboh 2011:624-631). Talking about the credulous manner in which postcolonial states in Africa copied and perpetuated the colonial system of administration including education, the Eritrean philosopher, Tsenay Serequeberhan, writes:

The institutional structures that the "independent" states of Africa have taken over from their former colonizers - the grounding parameters and cultural codes inscribed in these political, economic, educational, and social organizations-remain, in their essential constitution, oriented by colonial and European condescending attitudes. In every respect these vital societal structures remain unthought and unchanged. Thus, the unmasking and undoing of this Eurocentric residue on the level of theory is a basic task and challenge for African philosophic thought (T. Serequeberhan, 1994: 119).

The European "fortune seekers"(E. C. Eze, 1998) left the continent physically but did not leave spiritually, mentally and culturally as they left their 'institutions', 'cultural codes', churches, and method of social organization, behind. One of the primary reasons why European countries sought for colonies in Africa was to look for raw materials and market for their finished goods. To achieve this economic objective, they had to create a master/servant, and supremacy/dependency relation between the colonialists and the colonized. Hence, in order to have secretaries and junior staff to occupy the lower ranks of the colonial administration, to ease their predatory, proselytizing and mercantilic agenda, the colonialists promoted a system of education that was aimed at training workers to serve them. Colonial education was not meant to produce intellectually autonomous citizens, but perpetually dependent persons/nations. The Colonialists purposefully discouraged the industrialization of the continent. More than 50 years after 'independence', most African countries are just beginning to realize that they have simply unreflectively followed the system of education introduced by their former colonizers, and therefore falling into the ploy of the colonialists-education for under development.

The main problem with tertiary education is that it trains job seekers and not job creators. Professional and technological education trains job creators. Investment in professional and technical education may help reverse the situation. There may never be any genuine independence and total political, economic and cultural liberation in Africa until Africans engage in a serious, but rational2, investment in techno-scientific and professional education in general. Coupled with a predominantly tertiary educational system is the belief among the population that it is the responsibility of the government to provide employment for all its citizens.

Another important reason for age-cheating in Cameroon is the age limit for admission into public institutions that directly employs its graduates. In Cameroon, the age limit to take any exam into a public institution is 32 . In some schools, and for some jobs, the age limit is even lower. For example, in the military, it is between 18 and 21 for non-officers and between 21 and 25 for officers. For entrance into the Higher Teacher Training Colleges, it is 27 for the first cycle and 32 for the second cycle.

Furthermore, and closely linked to the above reason, is corruption in entrance exams into public institutions. Because there is age limit for entrance exams into most institutions of higher learning like the entrance into the Military Academy (EMIA) and into the military as a whole; the Faculty of Medicine and Biomedical Sciences (FMBS), the Police Academy (Ecole de Police); and the Higher Teacher Training College (Ecole Normale Supérieure, ENS), some graduates who have not been able to secure permanent jobs with the weak private sector(or simply because of job insecurity therein), or have failed the entrance exams into these institutions several times and want to avoid disqualification (for age reasons), in future, resort to age falsification.

In some cases, when the opportunity arises, usually when a family has a relation or someone from their tribe in some high position ingovernment (this may be a director, minister or anyone in an influential position) and for fear that they may not be in that position for long, such persons use all means possible to secure placesinto these institutions for their relations. At times these individuals do not only drastically reduce the ages of their relations, sometimes theygo as far as buying certificates for those who do not have the required certificates. In some institutionsyou may find mother and son or daughter, or father and son or daughter, in the same class with the former having the same age or barely older, and in some cases even younger than their progeny. The ethnicitization of appointments and promotions in the Cameroon public service, no doubt, has nefarious effects on the quality of service as most appointed officials use their offices to buy places for their children and relatives into institutions that train civil servants.It is in this light that Halleson argues that in most African countries, "the public

\footnotetext{
2 Rational in the sense that this should not involve an unreflective copying of Western values, but in carefully sifting those values in Western culture which are good and blending them with some positive aspects of indigenous values. The reason is that Western science and technology is couched in materialistic, individualistic, and monopolistic and profit-oriented philosophy which gives a blind eye to certain human values like compassion, the common good, etc. the prove of this is that in spite of the biotechnological revolutions the West has experienced, the gap between the affluent West (only about $15 \%$ of the world's population) and the rest of the world has rather been widening.
} 
service has emerged as a tool used by the political class to serve their private interest" (Halleson, 2011:75-84).

Moreover, most people fraud ages so as to work formuch longer and evade the trouble that comes with receiving your retirement dues coupled with the meager allowances that retired workers receive. Retirement, or even the thought of it, is an awful thing to most African civil servants. Mamadou Houmfa puts this fittingly when he writes:

In many African countries, government officials and political leaders do not want to hear about retirement, although legally they are usually expected to retire at 55 or 60. These government officials use various schemes to remain in office. Some obtain special extensions by presidential decree, while others often fraudulently lower their age to become 'officially' younger (Houmfa, 2013).

The main reason for the reluctance of most civil servants in Cameroon, for example, to retire is the low salarythey earn which cannot permit them to properlyprepare for retirement. In 1993 the Biya regime, at the heart of the economic crisis of $1990 \mathrm{~s}$, slashed the salaries of civil servants by $70 \%$ andsince then much has not changed despitethe rising cost of living in the country. Moreover, at retirement, civil servants receive only one third of their already paltry salary. For this reason, most civil servants simply want to get more than their fair share by falsifying their ages. It is for fear of retirement that most civil servants look for ways to cling so desperately to their positions at the expense of the unemployed youths. In doing so, they give very little in return as theyalso cheat in other ways, like dodging from work or arriving late to work. The lack of enthusiasm and inertia, complacency, inefficiency and arrogance common in the Cameroon public service today is very common among this category of civil servants. Some of those who stay full time at work either spend the whole time drinking alcohol or looking for Machiavellic means to extort money from the users of their services.

\section{Ethical Ramifications of Age-Cheating}

Cheating in all its forms is ethically wrong. It is a moral evilcondemned by all culturesalthough the intensity and response to it may vary from one culture to another.The argument that age-cheating is morally wrong may sound absurd to some readers. It may be argued that the wrongness of age-cheating resides in nothing more than the fact that cheating violates the rules of a game and it is against common morality. Hence, cheating is wrong simply because it is cheating. To reason this way is to take the moral wrongness of cheating for granted. The issuehere, therefore, is, even if age-cheating, or cheating as a whole, is fundamentally wrong, what makes it morally wrong?

Age-cheating is unfair to honest citizens. An age-cheater receives through fraudulent means what honest people work hard for.Generally, when you cheat, you deprive those who are qualified of their legitimate rights. Allen avers: "Cheaters force us to work harder or consume less for their benefit"
(Allen 2004:28-57). For example, age cheaters, when they become tired and weak, continue to 'work' and earntheir full salaries, even if they just 'appear' at work and do little or nothing.A. Allen contends that:

One major conception why cheating others is wrong is that it is an injurious lack of reciprocity. By deviating from standards that others stick to, cheaters exempt themselves from standards of fair play, thereby injuring the legitimate interests of others, including others' interest in wealth, opportunity and self-respect (Allen 2004:28-57).

Cheating affects efficiency in the quality of service. The prevalence of age-cheating may result in an aging public service, inertia and an unproductive civil service.The phenomenon of age-cheating like corruption as a whole may be one of the misdemeanors which may hamper Cameroon's vision of becoming an emerging economy by 2035 .

According to Kantian ethics, an act is morally right if it is done out of duty, that is, by not flouting the law. "Duty is the necessity of action to be done out of respect for the law" (Kant, p.1000). Cheating is against the law. It does not suffice to cheat because everybody or most people cheat. In his categorical imperative Kant states that "you should act only according to the maxim whereby you can at the same time will that it should become a universal law" (Kant, 1001). Would everyone follow your action of age-cheating? Agecheating is not an act done out of duty, in respect of the law and cannot be a universal law.

Also, one needs to look at the intention for which people cheat in the first place. Kant says that "There is no possible of thinking of anything at all in the world, or even out of it, which can be regarded as good without qualification, except a good will" (Kant, First Sect., p. 995).However, even if our intention is to secure a job in a system characterized by high level of unemployment, injustice, nepotism and clientelism, two wrongs cannot make a right. "While such a will may not indeed be the sole and complete good, it must nevertheless be the highest good and the condition of all the rest, even of the desire for happiness...." (Kant, 997).

From a Kantian perspective, therefore, cheating is morally wrong because it is not an action done out of duty with good intention respecting the law, and it cannot be a universal law. Only actions performed from duty have "genuine moral worth" (Kant, p. 999). Therefore, age-cheating is not rational and is not morally right according toKant's deontological ethics; it treats others, competitors, as means and not as ends in themselves.

Another effect of inefficiency is the harm it may cause the society. There is a great danger for the population to have someone who passes for a nurse, medical doctor or teacher. Such poseurs and impostors are many in the Cameroon public service and that many African countries today (http://www.africanindependent.com/cam_corruption_ntemfa c01.html). Innocent citizens may be physically and/or intellectually harmed because of the incompetence of health workers and teachers. Teachers in particular are builders of the mind, the nation and the future. This may result in a 
vicious cycle where poorly trained and incompetent workers provide poor services to the public thereby intensifying underdevelopment.

Moreover, age-cheating correlates with cheating in other areas of life, like in "one's professional life and other misbehaviours" (Bouville, 2012). Cheating is an offence against common honesty. A cheat manipulates and uses the other asa thing - an instrument. An age-cheater is a dishonest person who, like a shoplifter, may always shoplift whenever the opportunity arises.

Age-cheating may become a source of intergenerational conflict as the old refuse to retire at the detriment of the youths. Because age-cheating is largely provoked by unemployment, poverty, corruption and bad governance, any attempt to eradicate it withoutcorresponding measures to combat its underlying causes, through the institution of strong democratic structures(to ensure checks and balances on established authority, accountability, transparency, justice and the rule of law), may bea source of violent conflict which may threaten the political stability of the nation. The youths could develop a feeling of resentment against the old, especially the ruling elite, for being unfair to them. This situation may create tension which may result in violent conflicts which may disrupt economic and social activities thereby directly impeding the development of the country.

Age-cheating also has socio-economic effects on a society. "An aging population is less entrepreneurial and ambitious and may therefore negatively affect economic productivity." Although, on the other hand, as some economists argue, "a mature population embodies a greater stock of human capital and experience, measured by employment-specific acquired skills (tenure) and employment-independent experience" (Furnkranz-Prskawetz and Fent, 2004), as for instance, in the academic domain; apart from those in the ruling class, this is not the category of persons I am concerned with in this paper. I am concerned with those who reduce their ages before entering into the public service. Thiscategory does not have the experience and know-how, and most of the times are less qualified, than those aging peopleor professionals who have been in the public service for long. This can be explained by the fact that age-cheating sometimes is just a tip of the ugly iceberg. Age cheats are forgers and most of the times also falsifyother important documents including certificates.

\section{Solutions to Age-Cheating: Some Suggestions}

Even though the biometric identification system was introduced in Cameroon in 1996, it has not reduced the problem of age-cheating, since those who have never had a national identity card or birth certificate before can stillintentionally falsify their age. With the biometric registration, it is difficult to have more than one identification paper without the collaboration or complicity of the officials charged with the issuing of identity cards. Some unscrupulous people have succeeded in having more than one identity card. Sometimes, others use corrupt means to have their data modified. Moreover, biometric registration does not register children at birth. So, if you are applying for a national identity card for the first time you may not have any problems even if you have falsified your age.

There is an urgent need to modernise and decentralise the civil registration system so that records on birth and death and other important personal information may be well preserved. This will help check age-cheating.

Moreover, there is the need to liberalize recruitment into the public service to allow people above 40 years and beyond to be employed if they have the experience and know-how. There are many professionals in diverse fields who have been trained and have worked abroad who would like to make a contribution to the development of their nations by sharing their experiences. But in the current situation where most African politicians distrust their citizens in the Diaspora, it may be difficult to achieve this goal. The Diaspora constitutes a huge reservoir of financial and human capital. They are usually the most educated and skilled and the wealthiest (not in all cases, however). The role of the Diaspora in the economic development of emerging economies in Asia and South America is capital. In their quest for economic development, China and India, for example, developed institutional and legal frameworks recognizing and persuading their diasporas to return and invest their (huge) capital and know-how at home (Anonymous, 2009). Most African countries lack such institutional structures. Rather, the political elite in most African countries treat their diaspora with suspicion, considering them (with their financial and intellectual strength and links with their host countries) as threats, sometimes they are considered as spies for their host nations, to their political power.

Moreover, the age limit concerning entrance exams into public institutions in Cameroon needs to bereviewed. For jobs that need both intellectual and especially physical ability like the armed forces, a certain age limit, say, between 18 and 25 , could be permitted. But for purely intellectual and experienced-required jobs in the industry and the academy, it could be extended beyond 32 years for experience and intellectual maturity comes with several years of research and intellectual activity.

Retirement is another important issue that calls for an open and honest public debate on how to make it more conducive and comfortable. When living conditions are difficult for the retired, most people will be reluctant to retire and people will always look for unscrupulous means to stick to their jobs and avoid retirement. The government needs to put in place legal or institutional structures to take care of retired civil servants. This will require removing the difficulties, hardship and frustration that comes with retirement. The meager pension and the difficulties involved in having it paid has resulted in the frustration and death of many retired civil servants even before they start receiving any.

Furthermore, there is the need for a paradigm shift in the educational system in most African countries. If there is 
going to be any sustainable development in Africa,African governments need a completereview of the kind of education they offer to the future generation. As I argued above, since independence, African countries have predominantly trained job seekers and not creators.As stated earlier, this is one of the central causes of age-cheating today in most African countries and in Cameroon in particular. By focusing on tertiary education, African countries have only perpetuated a policy calculatedly promoted by their erstwhile colonialists to keep Africa from any form of industrial and technological development. The Asian Tigers (Hong Kong, Singapore, South Korea and Taiwan), which are not as resource endowed as most African countries like Cameroon, and some of whom were poorer than most African countries in the 1960s, have become emerging economies thanks to heavy investment on techno-scientific and professional education. By investing in rapid industrialization and export, and above all, good governance, these countries have become not only the fastest growing economies, but also some of the richest nations in the world today.

With limited natural resources, the Asian Tigers have become the hub of global manufacturing in automobile, electronics and information technologies. Most African countries have all the necessary resources, human and natural, except the political will, to kick start an industrial revolution on the continent. Apart from the fact that African countries are endowed with the natural resources (they have iron ore, bauxite, gold, wood, diamond, and copper, among others) necessary for rapid industrialization,African countries have some of the best professionals in the scientific and technological sectors trained abroad and willing to return and contribute to the development of their respective countries, but are discouraged by the appalling business and working conditions at home. The irony is that the wealth of resources in Africahave rather become the cause of the most violent conflicts on the continent. This situation has been described as "resource curse" (Ali, 2010) as these natural resources are rather used to sponsor wars. The war in Liberia, Sierra Leon and the Congo aresome examples. Moreover, even where these resources are not used to sponsor violent conflicts, the countries depend solely on them for their economic development such that when the prices of these goods drop in the world market, they provoke severe economic, social and political crisis in the producing countries. Industrialization may help diversify the economy and lessen the economic, social and political danger of depending on a single natural resource. Industrialization will also require investing in energy and fighting against smuggling and competition from cheap goods from Asia.

Rapid industrialization is one of the secrets of the head start of the West and her economic and political dominion over other parts of the world. Post-independent African leaders in their quest for political, economic and cultural reconstruction did not quite understand this Western hoax to keep Africa underdeveloped during the colonial era.The educational system in most post-colonial African states needs to be completely reformed to give due and proper place to technical/industrial and professional training.

Furthermore, the difficulty involved in starting a business in most African countries is also an issue that needs reviewing. Africans in the diaspora have been playing a key role in the development of their respective countries (notwithstanding the hurdles), for example, they send remittances, which help in the education and health care of relativesback at home. Apart from this, they are also "investors, philanthropist, innovators, and first movers in the growth of important sectors such as tourism and in the development of human capital" (Agunias and Newland 2012, .3). One of the problems holding African countries back economically is the "unfavorable investment climate, particularly inappropriate infrastructure" (World Bank, 2012).This is a very important factor which has contributed to the development of Asian countries like China and India. A favourable investment climate may not only encourage Africans in the diaspora to invest, but may encourage foreign investors as well.

Improving on governance may also help curb corruption and other forms of cheating like age-cheating. The application of new Information and Communication Technologies (ICTs) in governancemay go a long way toreduce age falsification and double identity. Information and communication technologies and particularly,egovernance may help in ensuring transparency and accountability in this direction. E-Governance is the application of ICTs for delivering government services, exchange of information communication transactions, incorporation of various independent systems and services between government-to-citizens, government-to-business, government-to-government as well as back office processes and interactions within the whole government structure. Gupta and Panzardi define e-governance

as the transformative use of technology and networks to support the use of authority and power in a country (at all levels) not only through enabling rules, capacities, processes, behaviors, institutions, and traditions, but also transnationally and globally, involving various actors and mechanisms including individuals, as well as formal and informal institutions and entities. In this context, egovernment also supports fundamental elements of good governance such as democracy, democratic processes and institutions which reflect national circumstances, fundamental human rights, the rule of law and the independence of the judiciary, effective, just and honest government, openness, participation /inclusiveness, accountability, effectiveness and coherence (lists.w3.org/Archives/Public/public...ig/.../The_Role_of_ E-9-26-08.doc).

E-governance "uses electronic means to support and stimulate good governance" (Backus, 2001).E-governance may help end state power as a "supermarket state" (Olsen, cited by Gupta and Panzardi) where the state is in total control, and make way for a state in which power is truly in the hands of the citizens as they directly participate in 
decision-making on serious matters affecting the state. (lists.w3.org/Archives/Public/public...ig/.../The_Role_of_E9-26-08.doc).Through e-Governance,"government services will be made available to citizens in a convenient, efficient and transparent manner" (Backus, 2001). With this, it will be difficult for citizens to have double identification or to impersonate because personal information is available and accessible to all.E-governance has been attempted in some South American countries like Argentina and Brazil with relative success on good governance (lists.w3.org/Archives/Public/public...ig/.../The_Role_of_E9-26-08.doc). E-governance will help improve the civil status registry which will help check duplicity of identity, fake marriages, births and deaths.

These proposals may only be attained in a trulydemocratic society, which is regulated by the principles of justice (Rawls, 1990) and the rule of law.Good governance would promote accountability, transparency, and justicein the management of public affairs. This is important because besides the education of the public, there is the need for an independent and impartial judiciary to punish corrupt and unethical practices. If Cameroon is to achieve sustainable development, it must take strongmeasures to fight corruption, diversify its economy, invest in science and technology, and above all, promote good governance.As Amartya Sen fittingly argues, "Development requires the removal of major sources of unfreedom: poverty as well as tyranny, poor economic opportunities as wellas systematic social deprivation, neglect of public facilities as well asintolerance or overactivity of repressive states" (Sen, 1999, 3).

\section{Conclusion}

In this analysis I have shown that there is a close link between age-cheating and corruption because both involve the use of dishonest means to have an undue advantage over others. Corruption and age-cheating in particular are partly caused by leadership failure which leads to economic failure. The consequence of this is high rate of unemployment, poverty and the total collapse of moral values. Most African countries operate with obsolete civil registration systems that do not ensure proper, if any, documentation of persons at birth and at death, which makes age-cheating, falsification of documents, multiple identification, and impersonation very easy. It is also for this reason that you would easily find, or here talks about ghost workers in the payroll of most African states. Because the causes of age-cheating involve an interaction of political, economic, social and cultural factors, the solution to the problem must involve a holistic approach that takes all these interconnected causative factors into account. This must include a paradigm shift in the domain of education from a system of education that focuses on producing barely literate citizens to an educational system that promotes self-employment; extending the age limit for recruitment into the public service; encouraging or stimulating the private sector especially small and medium business holders; modernizing the civil registration system, and above all, sanctioning those who are guilty of age-fraud.

Moreover, bad governance and economic hardship may create a fertile ground for violent conflicts and political instability resulting in economic stagnation. For African countries to make any meaningful strides towards sustainable development, the governments must take serious steps to revise their educational systems, laying emphasis on technoscientific and professional education, fight all forms of corruption and promote good governance; and not just succumb to the vicissitude of chance as most African countries have done during the last 50 years. This paper has only examined the phenomenon of age-cheating as one form of corruption, its causes and ethical and social implications. I have not examined the issue of age grades which may also have some connections with the question of age-cheating.

\section{References}

[1] Agunias, D. R. and Newland, K. (2012). Developing a road map for Engaging the Diaspora in Development: A Handbook for Policymakers and Practitioners in Home and Host Countries, Geneva, International Organization for Migration.

[2] Ali, H. S. (2010). "Beyond the Resource Curse: Minerals and Global Development" Issues in Brief 12 January.

[3] Allen, A. L. (2004). "Cheating, the Big Mistake," in The New Ethics: A Guided Tour of the Twenty-First Century Moral Landscape, New York: Marimax Books, pp. 28-57.

[4] Anonymous, (2009). The Diaspora as an Economic Asset: How China and India use their Diaspora to Support their Economic Development, M.A. Dissertation, London of School of Economics and Political Science.

[5] Backus, Micheil. (2001). "E-Governance and Developing Countries: Introduction and Examples", Research Report, No. 3.

[6] Bouville M. "Why Cheating is wrong" (http://arxiv.org/ftp/arxiv/papers/1102/1102.1506.pdf, 12/03/2013).

[7] Cameroon Economic Update, Unlocking the Labour Force: An Economic Update on Cameroon with a Focus on Employment, January 2012.

[8] Cleveland, D. A. (1989). "Developmental Stage Age Groups and African Population Age Structures: The Kusasi of the West African Savanna" American Anthropologist.

[9] Eze, C. E.(1998). "Modern Western Philosophy and African Colonialism", in Emmanuel C. Eze (ed.), African Philosophy: An Anthology, Oxford, Blackwell Publishers.

[10] Backus, Micheil. (2001). "E-Governance and Developing Countries: Introduction and Examples", Research Report, No. 3.

[11] Bouville M. "Why Cheating is wrong" (http://arxiv.org/ftp/arxiv/papers/1102/1102.1506.pdf, 12/03/2013).

[12] Cameroon Economic Update, Unlocking the Labour Force: An Economic Update on Cameroon with a Focus on Employment, January 2012. 
[13] Ebai, J. E. and Forje, J. W(2009), Challenges of Administrative Reforms and Public Service Accountability in Africa : The case of Cameroon, Cameroon Journal of HumanRights and Democracy Vol. 3, Number 1 June 2009.

[14] Fürnkranz-Prskawetz, A. and Fent, T. (2004) "Workforce Aging and Economic Productivity: The role of Supply and demand of Labour: An Application to Austria" Current Issues of Economic Growth, No. 2.

[15] Guest, "Football Age, Real Age, and the Meanings of Age in Africa" http://pitchinvasion.net/blog/2009/08/11/football-agereal-age-and-the-meanings-of-age-in-africa/, 02/04/2013)

[16] Government Uncovers 1,050 'Age cheats in Civil Servicehttp://article.wn.com/view/2014/04/02/Govt_Uncovers _1050_Age_Cheats_in_Civil_Service/

[17] Gupta, T. and Panzardi R. "The Role of E-Government in Building Democratic Governance (with a special focus on LatinAmerica)"lists.w3.org/Archives/Public/public...ig/.../The _Role_of_E-9-26-08.doc (accessed 29/12/2013)

[18] Halleson, D. N. (2011). "The Charter for the Public Service in Africa: A Normative Framework for Public Service Reforms in Africa", Cameroon Journal on Democracy and Human Rights, Volume 5, Number 2, December 2011.

[19] Houmfa Mamadou. "African civil servants, please retire!" http://www.rnw.nl/english/article/african-civil-servantsplease-retire

[20] Kant, I. (1992). Grounding for the Metaphysics of Morals in Michael L. Morgan (ed.) Classics of Moral and Political Theory, Indianapolis, Hackett Publishing Company.

[21] Mbembe A.(1992). "Provisional Notes on the Postcolony", Journal of the International African Institute, Vol. 62, No. 1, pp. 3-37.

[22] Mhlanla, Z. "Turning back time: Age cheating in football" http://mg.co.za/article/2008-07-04-turning-back-time-agecheating-in-football

[23] Mbaku J.M. (2007).Corruption in Africa: Causes, consequences and cleanups, Plymouth, The Rowman and Littlefield Publishing Group, Inc.
[24] Mungazi, F. (2010). "Africa Kicks: Part Two", BBC http://www.misterdann.com/conaudafrica.htm, accessed $23 / 10 / 2013)$

[25] Museveni, Y. (2005) "The Power of Knowledge" in Bert Hamminga (ed.) Knowledge Cultures: Comparative Western and African Epistemology, Amsterdam, Rodopi.

[26] Nwel, T. P. (1999), Corruption in Cameroon, GERDDESCameroon, Yaoundé, Friederich-Ebert-Stiftung.

[27] Nyamnjoh, F. (1999). "Cameroon: A Country United by Ethnic Ambition and Difference", African Affairs.

[28] Oba, F. N. (2011). "Colonialism and Education" Proceedings of the 2011 International Conference on Teaching, Learning and Change (Ofege, T. (2004). Corruption in Cameroon : A State of the Art (http://www.africanindependent.com/cam_corruption_ntemfac 01.html, accessed 31/12/2013).

[29] Rawls, J. (1990). Political Liberalism, New York, Columbia University Press.

[30] Sen, A. (1999). Development as Freedom, New York, Alfred A. Knopf.

[31] Serequeberhan, T. (1994) The Hermeneutics of African Philosophy: Horizon and Discourse, New York, Routledge.

[32] Sinnot, J. and Molina, R. (2013). Football's age fraud: FIFA probes player with 'four birthdays' (http://edition.cnn.com/2013/02/01/sport/football/age-africanfootball-mbemba/index.html, accessed 17/12/2013).

[33] Shu, C. A. (2009). Cameroon: When Certificates Are CookedUp, Not Earned! (http://recorderline.blogspot.com/2009/06/cameroon-whencertificates-are-cooked.html accessed 17/12/2013)

[34] Tangwa, G. B.(2014). "Cameroon" in H.A.M.J. ten Have, B. Gordijn (eds.), Handbook of Global Bioethics,941-958 